\title{
Technology Instruction For Children With Learning Disabilities In Mathematics: Teacher's Views
}

Suza Hamira Suhaimin, Mohini Mohamed, NorulHuda Ismail*

Department of Educational Sciences, Mathematics and Creative Multimedia, UniversitiTeknologi Malaysia, Johor Bahru, Malaysia

*Corresponding author: p-norulhuda@utm.my

\begin{abstract}
The purpose of this paper is to examine the perspective of teachers regarding mathematics instruction for children with learning disabilities. For this purpose, a semi-structured interview was conducted with teachers who teach mathematics to children with learning disabilities. The participants of this study are three educators who teach children with learning disabilities. A qualitative strategy approach is used in this study using case studies. Information was acquired from interviews, document reviews and Brainstorming. The method of analysis involves the data transcription process, construction of themes, theme coding and displaying. The results of the research is analysed and recommendation for future research is stated. Intervention for children with Learning Disabilities is a challenge for both teachers and parents. Children with Learning Disabilities require special instructions in order to succeed and technology can help children depends on situation and teaching style.
\end{abstract}

Keywords: Instruction; learning disabilities; mathematics

CC 2017 Penerbit UTM Press. All rights reserved

\subsection{INTRODUCTION}

Today, education emphasizes on effective learning for students. In Malaysia, the education system is constantly changing due to provide better learning and allow students to enjoy the learning process. Children with Learning Disabilities (LD) too need effective learning to improve their understanding. Children with LD include Dyslexia, Autism, Attention Deficit Hyperactive Disorder (ADHD), Down's Syndrome (DS), and also those with hearing and speech disorders [1].

Learning Disabilities (LD) is defined as learning disorders caused by physical or mental disabilities and the difficulty of an individual in listening, speaking, reading, writing, reasoning, or mathematical abilities [2]. Most of them have problems in reading and Mathematics. Mathematics is not only arithmetic or to manipulate the numbers. It is used in daily life indirectly [3]. As an example, identifying time, ability to purchase items using monetary value and the use of distance. According to [4], individuals with learning disabilities who have problems in arithmetic would have a problem in balancing the budgeting finance and have problems pertaining the dollar cents. Therefore, understanding the concept of mathematics is very important for all individuals, as well as for children with LD.

Individuals having problems in mathematics is known as Dyscalculia. Dyscalculia is defined as academic skills in mathematics is below the average range in the culture and language of the appropriate tests, described in parallel by the development, neurological, sensory or motor disorders and to show a significant disruption to the academic performance of the work, or activities of daily living, [4].

Based on statistics from the Ministry of Education (MOE), the total number of children with LD is on the increase. This increase poses challenges to schools, teachers and parents of the children. The number of children at the primary level is and increasing since2010 to 2014. Figure 1 shows the increase of students each year. The Special Education Integration Year 2010-2014 is increasing as shown in Table 1. In line with this increase, effective teaching strategies need to be applied for a better and effective learning process. 


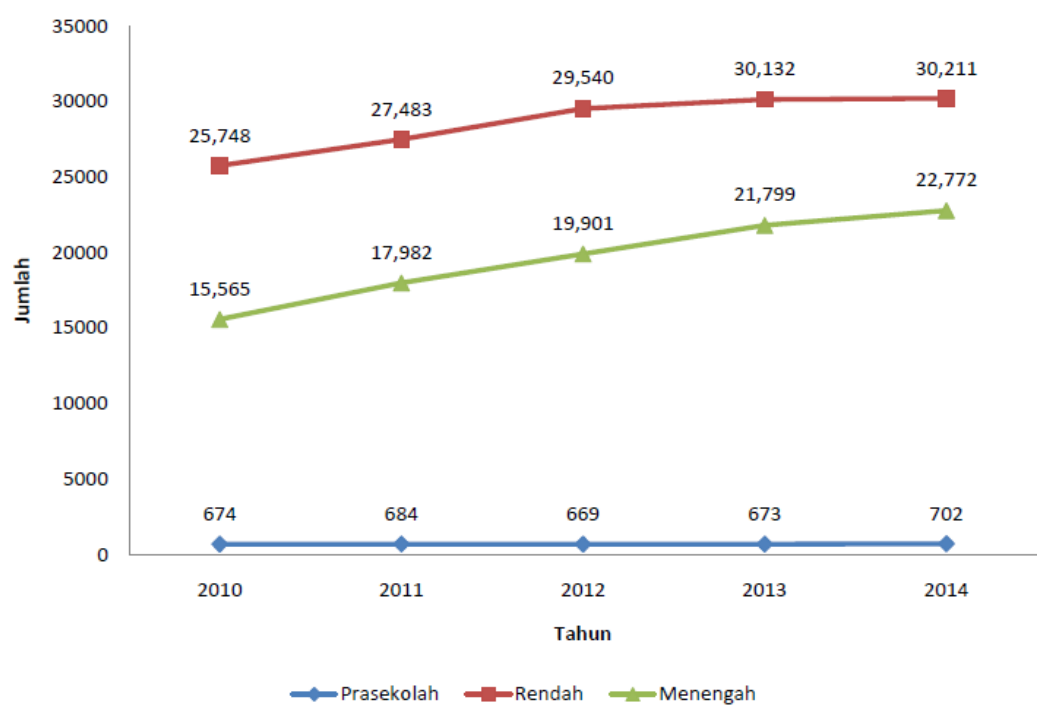

Figure 1 Statistic student with disabilities Source: Department Special Education

Table 1 Number of student with learning disabilities

\begin{tabular}{|l|c|l|l|l|}
\hline Level / Year & $\mathbf{2 0 1 0}$ & $\mathbf{2 0 1 1}$ & $\mathbf{2 0 1 2}$ & $\mathbf{2 0 1 3}$ \\
\hline Preschool & 144 & 149 & 157 & 162 \\
\hline Primary School & 4,223 & 4,319 & 4,518 & 4,743 \\
\hline Secondary School & 2,462 & 2,749 & 2,926 & 3,082 \\
\hline Total & $\mathbf{6 , 8 2 9}$ & $\mathbf{7 , 2 1 7}$ & $\mathbf{7 , 6 0 1}$ & 3,939 \\
\hline
\end{tabular}

There are various strategies of learning and material aids including the latest technology that can help children with LD in Mathematics.However, the effectiveness of technology to assist children with learning disabilities in Mathematics is not too deep be studied.

The article studied that technology is not suitable for children with LD. To help these children, appropriate strategies must be executed. The best selection strategies are for early childhood intervention because it is crucial for children with learning disabilities to continue to learn from primary until secondary level.

It is important to help children with LD to develop their working memory. Working memory has a specific relation to only a few but is important to develop early mathematics skills and language [5]. The ability to hold information in memory and processing the information is called working memory [6]. Working memory is a cognitive function that has implication on social, behavioural and academic performance. It is an important component in the educational task [7]. Based on previous studies, play game and paper exercise enhancement provide evidence suggesting that arithmetic performance not only provides enjoyment but also develop the working memory capacity [8].

Children with LD are poor in sensory skill [9]. Learning disorders are present if the sensory skill is lacking and need to be addressed [10]. Added sensory stimulation produce differential gains for both groups in reading recognition and comprehension and in math calculations and problem solving [11]. So, added sensory helps develop children's behavioural.

The Ministry of Health (MOH) and the Ministry of Education (MOE) recognise that early detection and intervention is critical and problems exists in the implementation of their programmes which they attribute to the lack of screening tools and the expertise to carry out assessments (Family Health Development Division, Ministry of Health, Health Care for Persons with Disabilities (2011 -2020), 2011 ). There is a lack of a more comprehensive identification procedure for children with disabilities, (Special Education Division, Ministry of Education, Setting Up a Multidisciplinary Framework for Early Identification and Intervention Support Services for Children with Disabilities, 2011). There is also lack of research on disabilities and also the absence of a well-concerted multidisciplinary team approach in identification and intervention process toaddress the needs of the child family.

However, early detection and intervention advocacy groups have identified other problems that contribute to the poor early detection and intervention process. Many specialists lack skills to adequately assess milder learning disabilities such as dyslexia, high functioning autism and dyspraxia. There is a serious lack of educational psychologists, developmental paediatricians, community paediatricians and other trained professionals in both the $\mathrm{MOH}$ and the MOE to aid in the assessment.

\subsection{OBJECTIVE}

From the above problems, the main objective of this study is to state the teacher's view in teaching mathematics for children with LD. It is important to know the teachers' view in order to know the teacher's skills in their teaching style. For this main objective, the research questions are as follows:

1. What are the views of teacher who teach children with Learning Disabilities vis-a-vis the importance of teaching mathematics?

2. What isthe teacher's opinion on the attitude of children during the learning process of mathematics? 
3. What are theteacher's views on teaching strategies that they are currently using for children with Learning Disabilities in mathematics?

4. Does the use of technology help children with learning disabilities in Mathematics

\subsection{METHODOLOGY}

\section{Research Design}

A qualitative strategy approach is used in this study using case studies. In this study, all participants were teachers from a private school teaching children with special needs. Three teachers were involved. All the participants volunteered to be involved in this study. Teacher A teaches children with Dyslexia in the state of Selangor. Teacher B is experienced in teaching children with Syndrome down and teacher C is experienced in teaching children with Dyslexia and Autism in a private school in Kuala Lumpur.

A semi structured interview form was used in this study. A form was designed with three main questions, and based on the answer sub questions supported the interview. Interview was recorded and documented. A brainstorming session was also conducted.

Data analysis is the process of understanding the meaning implied in an interview. The method of analysis involves the data transcription process, construction of themes, theme coding and displaying the results. The first step was to re-copy all data from the audio interview. Transcription of data was be done thoroughly without leaving anything during the hearing and observed. Data from the interview transcripts was re-read several times to identify main ideas by categories.

\subsection{RESULTS}

Below is the interview detail that was conducted on three special needs teachers.

The Importance Of Teaching Mathematics To Children With Special Needs

The respondents provided positive answers in relation to the importance of teaching mathematics to children with special needs. The use of numbers in daily life is one of the factors why mathematics is to be understood and learned. Some part of teachers answer like these:

"100\% agree need to learn Math" - (Teacher A)

"Concept of math is important for all" - (Teacher A)

"To use daily live, buying selling and other" - (Teacher A)

"All students should learn math" - (Teacher B)

"If Special needs children null basic in calculation, they easy will be cheat from others" - (Teacher B)

"Math is about money" - (Teacher C)

"Math is important to apply in daily life" - (Teacher C)

The Attitude Of Children During Process Of Teaching Mathematics

Feedbacks from the interview were appropriate and manageable. Because these teachers teach children with different abilities, so the answer may differ but relevant.

"They show an effort to learn. But they sometimes bored"- (Teacher A)

"Their failed in memorize and also confused" - (Teacher A)

"They lost in focuses and will make them Boredom to learn math!" - (Teacher B)

"Boredom because they not know understand" - (Teacher B)

"Main point, they not master in math" - (Teacher C)

"Problem in writing, reading will cause problem in arithmetic" - (Teacher C)

"Children cognitive are poor" - (Teacher C)

Views About Teaching Strategies In Mathematics

Teachers were asked question about the practices to of effective teaching. The answers provided varied.

"I used direct instruction, but sometimes used concrete" - (Teacher A)

"Technology is good but teacher need know how to use technology"- (Teacher A)

"I never used technology. Hahaha (loud)" - (Teacher A)

"I used appropriate material"- (Teacher B)

"Will see, they not boredom. Enjoy in their learning" - (Teacher B)

"Technology need spent more time" - (Teacher B) 
"In my opinion, technology can help children depends on situation" - (Teacher B)

"I used which is the best method to create interactive learning" - (Teacher C)

"Direct instructions and interactive materials are best instruction"- (Teacher C)

"For disability children, technology can help them in learning. We need to know what student disability. So that, we can minimise the problem" - (Teacher C)

Summary Findings

\section{Teacher A}

Teacher A mentioned that all students, normal or with special needs use numbers in their daily lives even though mathematics is the study of numbers. The most obvious example is buying and selling. The best methods should be given to children with special needs because it will affect the process of learning. Teacher A responded that children show effort to learn mathematics. Occasionally, they are bored if they are unable to master the basics. As an example, when children are confused with the language of mathematics, their concentration and focus will fade. They need for memorize and more practise. Teacher A mentioned that in her teaching strategies, she used direct instructions. Sometimes she used concrete objects to make children understand better, though both strategies were equally effective. Direct instructions helped students too. The use of technology was good if the teacher was able to apply effectively. However, she has never used technology in her teaching strategies.

\section{Teacher B}

Teacher B stated that Mathematics is very important for all children. The basic of mathematics is useful and used in daily life. Basic mathematics, comprising addition, subtraction, multiplication and division is very important. It is because children need to apply when they go to shop. If they have basic mathematics knowledge, at least they will not be deceived. As an example, children with Syndrome Down have same physical characteristics. They may easily be cheated if not careful in their mathematics. Teacher B also focused on boredom. Sometimes, they are happy and enjoy their learning even they did not master the basics. Nevertheless, sometimes the children's concentration too could drop. Teacher B used appropriate materials because her students like fun learning. The strategies used were based on the topic taught. Teacher B did not mention any specific strategies in her teaching method. According to her, the use of both strategies was equally good. Direct instructions need concrete object to maintain focus. Teacher B also stated that the teacher is the best mentor to make children successful in their learning. Appropriate strategies and models helped children. If the teacher did not supervise and did not use good teaching strategies, the children will not enjoy learning. In her opinion, technology instructions sometimes helped children in their learning. It depends on the situation. It is because the use of technology needs more time. That was why she avoided the use of technology.

\section{Teacher C}

Teacher $\mathrm{C}$ too stated that mathematics is important for all including children with special needs. For example, money, this is used in daily life. Mathematics is important to manage finance. A basic knowledge of mathematics and arithmetic is important. Teacher $\mathrm{C}$ mentioned that children with LD in other problem would cause them not master in math, such as their cognitive, especially in reading and writing. Video and audio recording can help children with reading and writing problems. Teacher $\mathrm{C}$ used direct instructions and interactive materials as teaching aids to create the children's interest in learning mathematics. Direct instruction approach is used when a child cannot use the materials provide. The need someone to help them to solve problems. In her opinion regarding the best strategy, interactive materials can help to improve children's understanding in learning mathematics. The attitude in children directly influences their learning style. How teachers manage children is also a factor in the teaching and learning of mathematics. Children with special needs require a more active approach to control their behaviour when at times it is unpredictable. Any strategy dependents on the topic taught and the children's disabilities. Teacher $\mathrm{C}$ was also not comfortable using technology to teach children. She did not give any reason.

\subsection{DISCUSSION}

From the study, all the responses from teachers who taught children with Learning Disabilities know the strategies for teaching mathematics. All of them stated that the important in the teaching of mathematics for children with special needs must be highlighted. These finding show consistency with [3]. Math is used in daily life. Children's attitude during mathematics learning provides positive responses. Children show interest in mathematics. However, sometimes they feel bored. They are bored because they do not understand and cannot follow the lesson the teacher teaches. Thus, we need to good strategies to create interest of the children as stated by[5]and [7].

Only Teacher B stated that the use of technology could help children in learning disabilities. However, there areconstraints when using technology in the learning process, especially involving children with learning disabilities. Teacher B said that sometimes technology could be the best strategy. It depends on the situation. They need more time to use technologies. That is why they avoid using technology. This answer is parallel with previous stud [15].

Previous studies focused on the use of technology as an instruction for the students to improve math proficiency. In addition to the use of technology, learning strategies are manipulative and centred teaching strategies and studies were conducted by researchers earlier [9] and [11]. All these studies showed an improvement in the children's understanding in learning mathematics. Teacher $\mathrm{C}$ suggested that to teach children is based on topics. Not all topics needed the same type of strategy for teaching purposes.

Typically, this study focuses on the early stages of a child's learning journey. Children need more attention and care compared to children who are normal [1]. It bothers various parties, especially parents themselves. In Malaysia, there is "Special Education Program" for 
these children to assist them in learning disabilities. This program is to educate children to be able to manage themselves without relying on the help of others [19].

\section{Technology as Instruction for Children with Learning Disabilities}

There are many articles which propose technology aided teaching strategies for children with learning disabilities, [20]. Technology is one of the potential learning tools for helping children with special needs to overcome the difficulties in learning basic mathematics. This is because technology makes children more active in learning as it is interactive, which can increase the motivation of children to focus on learning. The technology also provides a meaningful learning experience for students, [12]. One of the features that appear in Multiple Intelligence theory is to produce effective teaching. However, three of the teachers in this study did not use technology instruction to help children with special needs. Teacher B stated that the use of technology needed more time. It is different from study [21].Technology can help children in learning but it must involve small groups through interactive white board technology. To use technology in teaching, we need to know more, such as the children's ability.

\section{Technology Assist Children with Learning Disabilities}

Based on the responses and comparison with previous research, technology can help children in their learning process. Teachers failed to apply technology for children with special needs because of some issues that have not been identified. Figure 2 below is suggestion framework technology instruction for children with learning disabilities. The combination answers answers from the three teachers and previous studies.

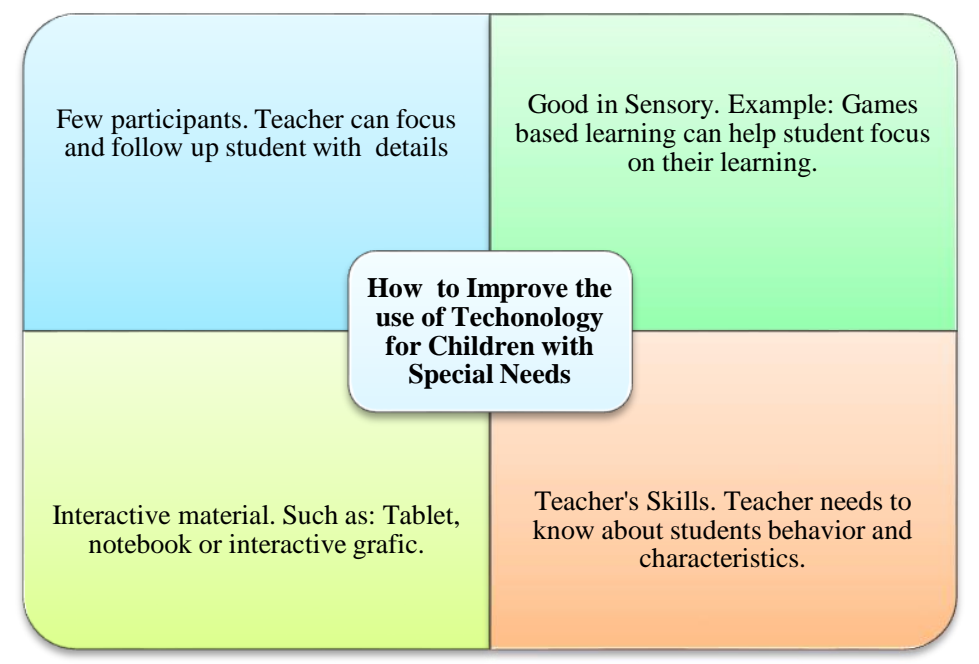

Figure 2 Suggestion framework technology instruction for children with learning disabilities

Arithmetic problem requires effective teaching to enhance the understanding and skills of children in numeracy. Teaching is a process related to the dissemination of knowledge for children to learn and to master and use in daily life. The process is meant to explain this teaching is a fact related to the theory. Learning theory refers to the legal principles of learning and learning produced by psychologists. In teaching, theory is very important to know the learning problems in addition to learn teaching techniques that can be used [22]. Based on the Multiple Intelligence theory, another study can focus on this theory in-depth, which has eight characteristics of intelligence. Each child has different intelligence.

However, there are also children who have all the features listed. Because of the answer on children attitude is different, teachers can follow Multiple Intelligence to improve teaching strategies.

\subsection{CONCLUSION}

Studies reported by [23], [24] and [25] using manipulative strategies in their instruction showed positive result for children with special needs. This study incorporates all the features in a Multiple Intelligence theory to determine the intelligence of the students in the learning thus facilitating the process of teaching. It is consistent with the answer from the participantswho prefer to use manipulative strategies on children with learning disabilities. The expectations for children to use manipulative or representations have increased over the past 10 years [26], [27].

In conclusion, intervention for children with Learning Disabilities is a challenge for both teachers and parents. Children with Learning Disabilities require special instructions in order to succeed. The study focuses on a variety of interventions in an attempt to find the best way to instruct children with Learning Disabilities. Comparing which intervention method may be suitable for each type of disability, may help teacher choose the right instructions in the learning process and may help children acquire the essential skills they will need in their life journey. [28] 


\section{References}

Aydemir, T. (2013). The VIEws of Special Education Teachers about Mathematics Instruction in Special Education. Procedia - Social and Behavioral Sciences, 106, 3133-3140.

Brown, D. J., Ley, J., Evett, L., \& Standen, P. (2011). Can Participating in Games Based Learning Improve Mathematic Skills in Students with Intellectual Disabilities? 2011 IEEE 1st International Conference on Serious Games and Applications for Health, SeGAH 2011, 16-18 November 2011.

Bryant, D. P., Bryant, B. R., \& Pfannenstiel, K. H. (2015). Mathematics Interventions: Translating Research Into Practice. Intervention in School and Clinic, 50(5), 255256.

Calik, N. can, \& Kargin, T. (2010). Effectiveness of the Touch Math Technique in Teaching Additio Skills to Students with Intellectual Disabilities. International Journal of Special Education, 25(1), 195-204.

Campbell, M. L., \& Mechling, L. C. (2008). Small Group Computer-Assisted Instruction With SMART Board Technology: An Investigation of Observational and Incidental Learning of Nontarget Information. Remedial and Special Education, 30(1), 47-57.

Castellar, E. N., All, A., Marez, L. de, \& Looy, J. Van. (2015). Cognitive Abilities, Digital Games and Arithmetic Performance Enhancement: A study Comparing the Effects of a Math Game and Paper Exercises. Computers and Education, 85, 123-133.

Cihak, D. F., \& Foust, J. L. (2008). Comparing Number Lines and Touch Points to Teach Addition Facts to Students With Autism. Focus on Autism and Other Developmental Disabilities, 23(3), 131-137.

Costley, K. C. (2014). Positive Effects of Technology on Teaching and Student Learning. Technical Report. Arkansas Tech University.

Doabler, C. T., Cary, M. S., Jungjohann, K., Clarke, B., Fien, H., Baker, S. \& Chard, D. (2012). Enhancing Core Mathematics Instruction for Students At Risk for Mathematics Disabilities. Teaching Exceptional Children, 44(4), 48-57.

Janier, J. B., Shafie, A., Taha, M. F., Mohamad, N. B., Fatimah, W., \& Ahmad, W. (2015). Need Analysis for Down Syndrome Children to Develop a Learning Material on Numbers with the Aid of Multimedia Technology. International Journal of Social Science and Humanity, 5(1), 3-7.

Kercood, S., Grskovic, J. a., Banda, D., \& Begeske, J. (2014). Working Memory and Autism: A Review of Literature. Research in Autism Spectrum Disorders, 8(10), $1316-1332$.

Kroesbergen, E. H. (2007). Working Memory and Early Mathematics: Possibilities for Early Identification of Mathematics Learning Disabilities. International Perspectives (Advances in Learning and Behavioral Disabilities), 20, 1-19.

Lin, C. Y., Lin, H. H., Jen, Y. H., Wang, L. C., \& Chang, L. W. (2011). Interactive Technology Application Program of Experience Learning for Children with Developmental Disabilities. Advanced Materials Research, 267, 259-264.

Lovelace, T. S., Jr, L. G., \& Tabb, J. (2015). Learning Disabilities : Practice Concerns And Students With LD Response to Intervention Techniques and Students with Learning Disabilities Article information : Advances in Special Education , 25. Emerald Group Publishing Limited.

Ministry of Education. (2013). Children with Disabilities in Malaysia.

Mohd Zuri Ghani, \& Aznan Che Ahmad. (2011). Kaedah dan Strategi Pengajaran kanak-kanak Bekeperluan Khas. (Norazlina Abd Halim, Ed.) (1st ed.). Penerbit Universiti Sains Malaysia.

Monari Martinez, E., \& Benedetti, N. (2011). Learning Mathematics in Mainstream Secondary Schools: Experiences of Students with Down's Syndrome. European Journal of Special Needs Education, 26(4), 531-540

Pesova, B., Sivevska, D., \& Runceva, J. (2014). Early Intervention and Prevention of Students with Specific Learning Disabilities. Procedia - Social and Behavioral Sciences, 149, 701-708.

Purpura, D. J., \& Ganley, C. M. (2014). Working Memory and Language: Skill-Specific or Domain-General Relations to Mathematics? Journal of Experimental Child Psychology, 122, 104-121.

Satsangi, R., \& Bouck, E. C. (2014). Using Virtual Manipulative Instruction to Teach the Concepts of Area and Perimeter to Secondary Students With Learning Disabilities. Learning Disability Quarterly, 38(3), 174-186.

Shin, M., \& Bryant, D. P. (2015). A Synthesis of Mathematical and Cognitive Performances of Students With Mathematics Learning Disabilities. Journal of Learning Disabilities, 48(1), 96-112.

Simon, R., \& Hanrahan, J. (2004). An Evaluation of the Touch Math Method for Teaching Addition to Students with Learning Disabilities in Mathematics. European Journal of Special Needs Education, 19(2), 191-209.

Skiada, R., Soroniati, E., Gardeli, A., \& Zissis, D. (2014). EasyLexia: A Mobile Application for Children with Learning Difficulties. Procedia Computer Science, 27, $218-228$.

Soares, N., \& Patel, D. R. (2015). Dyscalculia. Nova Science Pub, 8(1), 15-26.

Wah, W. K., Khairuddin Mohamed, Maridah Alias, Rashinawati Abd Rashid, \& Azlina Ahmad. (2013). Kanak-Kanak Keperluan Khas. In W. K. Wah (Ed.), Perkembangan Kanak-Kanak. Selangor: Oxford Fajar.

Wright, C. M., \& Conlon, E. G. (2009). Auditory and Visual Processing in Children with Dyslexia. Developmental Neuropsychology, 34(3), 330-55.

Wu, T.-F., Chen, M.-C., Yeh, Y.-M., Wang, H.-P., \& Chang, S. C.-H. (2014). Is Digital Divide An Issue for Students with Learning Disabilities? Computers in Human Behavior, 39, 112-117.

Zentall, S. S., Tom-Wright, K., \& Lee, J. (2013). Psychostimulant and Sensory Stimulation Interventions That Target the Reading and Math Deficits of Students with ADHD. Journal of Attention Disorders, 17(4), 308-329. 